\title{
Ongoing Electroencephalographic Rhythms Related to Exploratory Movements in Transgenic TASTPM Mice
}

\author{
Claudio Del Percio ${ }^{a}$, Wilhelmus Drinkenburg ${ }^{b}$, Susanna Lopez $^{\mathrm{a}, \mathrm{c}}$, Maria Teresa Pascarelli ${ }^{\mathrm{d}}$, \\ Roberta Lizio $^{\mathrm{e}}$, Giuseppe Noce ${ }^{\mathrm{e}}$, Raffaele Ferri ${ }^{\mathrm{d}}$, Jesper Frank Bastlund ${ }^{\mathrm{f}}$, Bettina Laursen ${ }^{\mathrm{f}}$, \\ Ditte Zerlang Christensen ${ }^{\mathrm{f}}$, Jan T. Pedersen ${ }^{\mathrm{f}}$, Gianluigi Forloni ${ }^{\mathrm{g}}$, Angelisa Frasca ${ }^{\mathrm{g}}$, \\ Francesco M. Noèg ${ }^{\text {, Paolo Francesco Fabene }}{ }^{\mathrm{h}}$, Giuseppe Bertini ${ }^{\mathrm{h}}$, Valeria Colavito ${ }^{\mathrm{h}}$, \\ Marina Bentivoglio $^{\mathrm{h}}$, Jonathan Kelley ${ }^{\mathrm{b}}$, Sophie Dix ${ }^{\mathrm{i}}$, Francesco Infarinato ${ }^{\mathrm{j}}$, Andrea Soricelli ${ }^{\mathrm{e}, \mathrm{k}}$, \\ Fabrizio Stocchi ${ }^{1}$, Jill C. Richardson ${ }^{\mathrm{m}}$ and Claudio Babiloni ${ }^{\mathrm{a}, \mathrm{n}, *}$ on behalf of PharmaCog Consortium \\ a Department of Physiology and Pharmacology "V Erspamer", Sapienza University of Rome, Rome, Italy \\ ${ }^{\mathrm{b}}$ Janssen Research and Development, Pharmaceutical Companies of J\&J, Beerse, Belgium \\ ${ }^{\mathrm{c}}$ Department of Emergency and Organ Transplantation - Nephrology, Dialysis and Transplantation Unit, Aldo \\ Moro University of Bari, Bari, Italy \\ ${ }^{\mathrm{d}}$ Oasi Research Institute - IRCCS, Troina, Italy \\ ${ }^{\mathrm{e}}$ IRCCS SDN, Naples, Italy \\ ${ }^{\mathrm{f}} H$. Lundbeck A/S, Valby, Denmark \\ ${ }^{\mathrm{g}}$ Department of Neuroscience, Istituto di Ricerche Farmacologiche Mario Negri IRCCS, Milan, Italy \\ ${ }^{\mathrm{h}}$ Department of Neurological Biomedical and Movement Sciences, University of Verona, Verona, Italy \\ ${ }^{\mathrm{i}}$ Eli Lilly, Erl Wood Manor, Windlesham, Surrey, UK \\ jIRCCS San Raffaele Pisana, Rome, Italy \\ ${ }^{\mathrm{k}}$ Department of Motor Sciences and Healthiness, University of Naples Parthenope, Naples, Italy \\ ${ }^{1}$ Institute for Research and Medical Care, IRCCS San Raffaele Pisana, Roma, Italy \\ ${ }^{\mathrm{m}}$ GlaxoSmithKline R\&D Neurotherapeutics Area UK, Gunnels Wood Road, Stevenage, Hertfordshire, UK \\ ${ }^{\mathrm{n}}$ San Raffaele Cassino, Cassino (FR), Italy
}

Accepted 11 August 2020

\begin{abstract}
. cognitive deficits. examined in four research centers of the PharmaCog study.

\footnotetext{
${ }^{*}$ Correspondence to: Prof. Claudio Babiloni, PhD, Depart-
} ment of Physiology and Pharmacology "V Erspamer", Sapienza University of Rome, P.le A. Moro 5, 00185 Rome, Italy. Tel./Fax: +390649910989 0917; E-mail: claudio.babiloni@uniroma1.it.
\end{abstract}

Background: The European PharmaCog study (http://www.pharmacog.org) has reported a reduction in delta (1-6 Hz) electroencephalographic (EEG) power (density) during cage exploration (active condition) compared with quiet wakefulness (passive condition) in PDAPP mice (hAPP Indiana V717F mutation) modeling Alzheimer's disease (AD) amyloidosis and

Objective: Here, we tested the reproducibility of that evidence in TASTPM mice (double mutation in APP KM670/671NL and PSEN1 M146V), which develop brain amyloidosis and cognitive deficits over aging. The reliability of that evidence was

Methods: Ongoing EEG rhythms were recorded from a frontoparietal bipolar channel in 29 TASTPM and 58 matched "wild type" C57 mice (range of age: 12-24 months). Normalized EEG power was calculated. Frequency and amplitude of individual delta and theta frequency (IDF and ITF) peaks were considered during the passive and active conditions. 
Results: Compared with the "wild type" group, the TASTPM group showed a significantly lower reduction in IDF power during the active over the passive condition $(p<0.05)$. This effect was observed in 3 out of 4 EEG recording units.

Conclusion: TASTPM mice were characterized by "poor reactivity" of delta EEG rhythms during the cage exploration in line with previous evidence in PDAPP mice. The reliability of that result across the centers was moderate, thus unveiling pros and cons of multicenter preclinical EEG trials in TASTPM mice useful for planning future studies.

Keywords: Active and passive state in wakefulness, Alzheimer's disease, electroencephalography, TASTPM mice, wild type mice

\section{INTRODUCTION}

Alzheimer's disease (AD) is the most prevalent progressive neurodegenerative dementing disorder across aging [1-3]. In the new diagnostic criteria [4], AD can be diagnosed before any cognitive or behavioral symptoms (preclinical stage) and in the mild cognitive impairment (MCI, prodromal stage) and dementia stage.

Among the topographic markers for tracking the $\mathrm{AD}$ progression, a promising variable derives from ongoing cortical electroencephalographic (EEG) rhythms in wakefulness $[5,6]$. Those EEG rhythms might be generated by the spatial summation of postsynaptic potentials, which might be provoked by the temporal synchronization/desynchronization at given frequencies of a large number of cortical pyramidal neurons by neurotransmitters released by cortical and subcortical (i.e., thalamic, basal forebrain, brainstem) neurons [7].

Two main conditions are typically used to probe these neurophysiological synchronization and desynchronization mechanisms in a clinical setting in humans. In a "passive" behavioral condition, the subject remains in relaxed wakefulness (resting state) with eyes closed for a few minutes. This mode is contrasted with a more "active" behavioral condition in which the subject remains in relaxed wakefulness with eyes open for a few minutes (monitoring the surrounding environment). In the resting state eyesclosed condition, EEG rhythms show the highest power (density) at about 8 and $12 \mathrm{~Hz}$ in posterior cortical areas, the so-called dominant alpha rhythms [8]. After eyes opening, alpha rhythms exhibit a power reduction (i.e., desynchronization or "reactivity") as a reflection of increased cortical arousal related to augmented vigilance [8].

Previous studies have reported differences in absolute and relative EEG power in normal elderly (Nold) subjects compared with $\mathrm{AD}$ patients in a resting state eyes-closed condition. As compared to Nold subjects, AD patients with dementia showed a higher power of widespread delta $(<4 \mathrm{~Hz})$ and theta $(4-7 \mathrm{~Hz})$ rhythms, associated with lower power of posterior alpha $(8-12 \mathrm{~Hz})$ and beta $(13-20 \mathrm{~Hz})$ rhythms [9-15].

Absolute and relative resting-state EEG power exhibited differences between AD and Nold subjects also in the "reactivity" from the eyes-closed to the eyes-open condition. Compared with Nold subjects, AD patients with dementia and MCI showed a lower "reactivity" of posterior alpha rhythms, namely a reduced difference between the EEG (and magnetoencephalographic, MEG) power during the eyes-open and -closed condition [16-22]. This lower "reactivity" may be due to both smaller alpha rhythms in $\mathrm{AD}$ over Nold subjects during the eyes-closed condition and impaired basal forebrain cholinergic neurotransmissions in the transition from eyes-closed to eyes-open condition as revealed by recent multimodal resting-state functional magnetic resonance imaging and EEG findings [23].

An interesting issue is the extent to which ongoing EEG rhythms are abnormal in transgenic mouse models of $\mathrm{AD}$, taking into account the significant differences in the structural and functional features of brain neurophysiological mechanisms underpinning the generation of EEG activity and the regulation of vigilance in the two species.

A wealth of studies has documented an abnormal brain electrical activity (i.e., hyper-synchronous activities) as revealed by EEG signals in APP- and PS1-mutated transgenic models showing progressive amyloidosis in the brain [24-37].

The European Innovative Medicine Initiative (IMI) project entitled "PharmaCog" (2010-2015) aimed at validating EEG biomarkers in AD clinical and preclinical trials (Grant Agreement $\mathrm{n}^{\circ} 115009$, http://www.pharmacog.org). In the PharmaCog clinical studies, cortical EEG sources at both delta and alpha rhythms 1) differed in ADMCI than healthy control participants during eye-opening in the resting state condition [18] and 2) were more abnormal in ADMCI than control non-AD MCI patients during eyes-closed resting state condition $[37,38]$. 
In the PharmaCog preclinical studies, ongoing EEG activity was recorded in C57BL/6 mice with and without genetic mutations of $A P P$ or $A P P$ and $P S 1$ genes (for the sake of simplicity, we termed C57BL/6 mice without those genetic mutations as "wild type", WT). The data analysis design was focused on the comparison of ongoing EEG activity in two behavioral conditions, namely a condition of immobility or minimal movements in wakefulness (passive condition) and a condition of exploratory movements related to a greater level of brain arousal associated with attention, sensory, and cognitive-motor processes (active condition). In two previous articles, the PharmaCog Consortium published the following findings $[39,40]$. Compared with the passive condition, the active condition was characterized by 1) a decrease in cortical delta power and 2) an increase in cortical theta power. In the passive condition, the cortical delta power was higher in the old WT group (i.e., 20-24 months of age) than the middle-aged (i.e., 12-15 months of age) and young (i.e., 4.5-6 months of age) ones [50]. In the active condition, the cortical theta power was higher at $6-8 \mathrm{~Hz}$ in the old WT group and $8-10 \mathrm{~Hz}$ in the young WT group [39]. In WT and PDAPP (hAPP Indiana V717F mutation inducing abnormal neural transmission, cognitive deficits, and brain accumulation of $A \beta_{1-42}$ ) mice with 20-24 months of age, the WT but not the PDAPP group exhibited a reduction (reactivity) in delta and theta power during the active over the passive condition [40].

In the present study, we report the original results of a third PharmaCog EEG study performed in TASTPM mice (age of 12-24 months), which harbor the Swedish double familial mutation (K670N, M6781L) of the human APP gene and the familial mutation (M146V) of the human Presenilin 1 (PS1) gene, both under control of the murine Thy-1 promoter. The present study tested two novel hypotheses: 1) Reactivity in EEG rhythms in the active over the passive condition may be poor in TASTPM mice, thus corroborating previous evidence in PDAPP mice [40]; 2) This effect may be reliably observed in all four preclinical EEG recording units of the present study.

\section{METHODS}

\section{Animals}

In the present study, 29 TASTPM mice (14 females; mean age: 15.3 months \pm 0.7 standard error,
Table 1

Features of the C57 (for the sake of simplicity, wild-type, WT) and the TASTPM mice for the following electroencephalographic (EEG) recording units: Janssen Research and Development (Belgium), H. Lundbeck A/S (Denmark), Mario Negri Institute (Italy), and University of Verona (UNIVR, Italy). F, female; M, male

\begin{tabular}{lcccc}
\hline & Centre & $\mathrm{N}$ & Sex $(\mathrm{F} / \mathrm{M})$ & Age \\
\hline WT & Janssen & 12 & $5 \mathrm{~F} / 7 \mathrm{M}$ & 12 months \\
& Lundbeck & 22 & $14 \mathrm{~F} / 8 \mathrm{M}$ & 15,24 months \\
& MNI & 15 & $15 \mathrm{M}$ & $12,14,24$ months \\
\multirow{4}{*}{ TASTPM } & UNIVR & 9 & $9 \mathrm{M}$ & 12,20 months \\
& Janssen & 9 & $5 \mathrm{~F} / 4 \mathrm{M}$ & 12 months \\
& Lundbeck & 9 & $9 \mathrm{~F}$ & 15 months \\
& MNI & 8 & $8 \mathrm{M}$ & 14,24 months \\
& UNIVR & 3 & $3 \mathrm{M}$ & 20 months \\
\hline
\end{tabular}

SE; range of age: 12-24 months) and 58 matched C57 WT mice were included (19 females; mean age: 17 months $\pm 0.7 \mathrm{SE}$; range of age: $12-24$ months) were used (see Table 1). The age of the TASTPM mice ensured the presence of severe $A \beta$ plaques deposition in the brain. The data were collected from 1 Belgian center (Janssen Research and Development; 9 TASTPM and $12 \mathrm{WT}$ mice), 1 Danish center $(\mathrm{H}$. Lundbeck A/S; 9 TASTPM and 22 WT mice), and 2 Italian centers (Mario Negri Institute for Pharmacological Research of Milan, 8 TASTPM and 15 WT mice; University of Verona, 3 TASTPM and 9 WT mice). Statistical analyses were performed to compare the age ( $t$-test) and sex (Fisher exact test) of the two mouse groups (i.e., TASTPM and WT; significance threshold: $p<0.05$, two-tailed). Results showed no significant difference (age: $p>0.1$; sex: $p>0.15)$.

Procedures involving mice and their care were conducted in line with the institutions' guidelines, in strict conformity with national and international laws and policies (EEC Council Directive 86/609, OJ L 358, 1, 12 December 1987; U.S. National Research Council, 1996, Guide for the Care and Use of Laboratory Animals). The respect of these guidelines was carefully controlled by the members of WP8 of the IMI PharmaCog project, devoted to the ethics of research.

\section{Pre-surgery (3 weeks)}

For at least three weeks before surgery, the mice were acclimatized. They were housed at a constant temperature $\left(18-22^{\circ} \mathrm{C}\right)$ and relative humidity (55-65\%) under a standard $12 \mathrm{~h}$ light/dark cycle (light-on hemicycle typically spanning from 6:00 a.m. to 6:00 p.m.) with free access to food and water. After surgery, the animals were housed in 
individual cages at the same conditions (typical cage size was $45 \mathrm{~cm}$ [length] $\times 24 \mathrm{~cm}$ [width] $\times 20 \mathrm{~cm}$ [height]). Light intensity was $90-1101 \times$ in the room, $60 \mathrm{l} \times$ in the cage during the light period, and less than $11 \times$ during the dark period. Gentle handling for about 5-10 min was applied daily to reduce the potential stress due to housing and experimenters. Such stress was evaluated continuously along with all the duration of the experiments by veterinary experts of each center. These experts tested animal muscle relaxation and standard behavioral indices of stress in freely behaving mice (i.e., preservation of exploratory movements in the cage, preservation of instinctual activities such as drinking and eating, and body weight across pre- and post-surgical days).

\section{Surgery}

EEG electrodes were implanted after anesthesia performed by inhalation of isoflurane $(5 \%)$ or Equithesin, pentobarbital $(1 \%)$, and chloral hydrate $(+4 \%)$ $3.5 \mathrm{ml} / \mathrm{kg}$ ). The mice were also treated with systemic analgesics and antibiotics in line with local guidelines on surgical care.

For the MNI and Lundbeck recording units, a tethered system for EEG recordings was used. Stainless-steel insulated surface epidural electrodes were used as exploring contacts at the frontal and parietal sites (model E363/20 with a diameter of $0.56 \mathrm{~mm}$ (0.022 $\prime)$; PlasticsOne, VA, US). One depth electrode as a reference contact was implanted in the cerebellum; another depth electrode as a ground contact was implanted in the temporal bone without the removal of the muscles (model E363/1 with a diameter of $0.280 \mathrm{~mm}(0.011 / \prime)$, PlasticsOne, VA, US). The electrodes were fixed to the skull with dental cement. EEG signals were transmitted through a plastic electrode pedestal and a connector cable to the amplifier with a maximal cable length of $50 \mathrm{~cm}$.

For the Janssen and UNIVR recording units, a telemetric system for EEG recordings was used. Mice were instrumented with a radio-telemetry probe F20-EET (DSI, MN, USA) containing sensors for the recording of the EEG, electromyogram (EMG), body temperature, and locomotion. The probe was implanted in the peritoneal cavity with $1 \mathrm{~mL}$ of sterile physiological saline to prevent desiccation. The four leads were subcutaneously tunneled from the peritoneal cavity towards a $1-\mathrm{cm}$ head skin incision. Bipolar EEG recordings were performed by two miniature stainless-steel screw electrodes.
These EEG electrodes were epidurally implanted on parietal and frontal cortical areas and fixed to the skull with acrylic dental cement (stereotaxic coordinates: Reference, AP: -6 , ML: +2 ; Ground, AP: -2 , ML: +2.5; Frontal, AP: +2.8, ML: -0.5 ; Parietal AP: -2 , ML: +2) [41]. Bipolar EMG recordings were performed by two other electrodes placed in the dorsal neck muscles. These EEG and EMG electrodes (EEG and EMG) had an outer diameter of $0.3 \mathrm{~mm}$.

\section{Quiet post-surgery period (1 week)}

The mice were treated with systemic analgesics and antibiotics during a standard post-surgical period of one week. The week immediately after surgery, animals underwent a period of recovery with neither handling treatment nor EEG recordings.

\section{Handling post-surgery period (1 week)}

In the week after the quiet post-surgery period, EEG was not recorded, but gentle handling was applied for about 2-5 min daily, and the animals were gently plugged and unplugged several times (for wired systems only) across that week to familiarize with the procedure.

\section{Experimental day}

EEG experiments were performed during both the dark and light phases. During the EEG recording period, the mice received no handling treatment. EEG recordings started after the second hour of the beginning of light or darkness. The sampling frequency of EEG recordings was performed at least $250 \mathrm{~Hz}$ with anti-aliasing bandpass analogue filters (Janssen: $250 \mathrm{~Hz}$, Lundbeck: $1000 \mathrm{~Hz}$, MNI: $1600 \mathrm{~Hz}$, UNIVR: $500 \mathrm{~Hz} ; 0.16 \mathrm{~Hz}-100 \mathrm{~Hz}$ passband filter). No notch filter was used.

Table 2 summarizes the time flow of the treatments and procedures adopted in the experimental sessions (days are referred to as the surgical event).

\section{Determination of the behavioral mode}

An essential step of the data analysis was the classification of animal behavior during the EEG recordings. The behavioral classification was performed by two independent experts in each recording unit). The two experts underwent a preliminary phase of training for the harmonization of procedures 
Table 2

Results of the main statistical analyses (ANOVAs) analyzing the comparisons of the frequency and normalized EEG power between the WT and TASTPM mouse groups

\begin{tabular}{|c|c|c|}
\hline Dependent Variable & ANOVA Design and Factors & $\begin{array}{l}\text { Interactions and Significant Results } \\
(p<0.05)\end{array}$ \\
\hline $\begin{array}{l}\text { Frequency bin of IDF } \\
\text { during passive condition } \\
\text { and ITF during active } \\
\text { condition in WT and } \\
\text { TASTPM mice }\end{array}$ & $\begin{array}{l}\text { 3-way ANOVA } \\
\text { Group (WT and TASTPM) } \\
\text { Unit (Janssen, Lundbeck, MNI, } \\
\text { and UNIVR) } \\
\text { Frequency (IDF, ITF) }\end{array}$ & - \\
\hline $\begin{array}{l}\text { Amplitude of normalized } \\
\text { EEG power density at ITF } \\
\text { and IDF in WT mice }\end{array}$ & $\begin{array}{l}\text { 3-way ANOVA } \\
\text { Unit (Janssen, Lundbeck, MNI, } \\
\text { and UNIVR) } \\
\text { Condition (passive, active) } \\
\text { Frequency (IDF, ITF) }\end{array}$ & $\begin{array}{l}\text { 2-way: Condition X Frequency }(F=214.1, \\
p<0.00001) \\
\text { Duncan post hoc: } \text { passive }>\text { active at IDF } \\
(p<0.00005) ; \text { active }>\text { passive at ITF } \\
(p<0.00005)\end{array}$ \\
\hline $\begin{array}{l}\text { Amplitude of normalized } \\
\text { EEG power density at ITF } \\
\text { and IDF in TASTPM mice }\end{array}$ & $\begin{array}{l}\text { 3-way ANOVA } \\
\text { Unit (Janssen, Lundbeck, MNI, } \\
\text { and UNIVR) } \\
\text { Condition (passive, active) } \\
\text { Frequency (IDF, ITF) }\end{array}$ & $\begin{array}{l}\text { 2-way: Condition X Frequency }(F=74.2, \\
p<0.00001) \\
\text { Duncan post hoc: } \text { passive }>\text { active at IDF } \\
(p<0.0001) \text {; active }>\text { passive at ITF } \\
(p<0.0001) \\
3 \text {-way: Unit X Condition X Frequency } \\
(F=11.8, p<0.0001) \\
\text { Duncan post hoc: passive }>\text { active at IDF in } \\
\text { Janssen }(p<0.001), \text { Lundbeck }(p<0.001), \\
\text { MNI }(p<0.005) \text {; active }>\text { passive at ITF in } \\
\text { Lundbeck }(p<0.001)\end{array}$ \\
\hline $\begin{array}{l}\text { Amplitude of normalized } \\
\text { EEG power density } \\
\text { (active minus passive) at } \\
\text { ITF and IDF in WT and } \\
\text { TASTPM mice }\end{array}$ & $\begin{array}{l}\text { 3-way ANOVA } \\
\text { Group (WT and TASTPM), } \\
\text { Unit (Janssen, Lundbeck, MNI, } \\
\text { and UNIVR) } \\
\text { Frequency (IDF, and ITF) }\end{array}$ & $\begin{array}{l}\text { 2-way: Group X Frequency }(F=13.2, \\
p<0.0005) \\
\text { Duncan post hoc: WT }>\text { TASTPM at IDF } \\
(p<0.0005) \\
\text { 3-way: Group X Unit X Frequency }(F=4.3 \text {, } \\
p<0.01) \\
\text { Duncan post hoc: WT }>\text { TASTPM at IDF in } \\
\text { Janssen }(p<0.0005), \text { MNI }(p<0.05), \\
\text { UNIVR }(p<0.0005)\end{array}$ \\
\hline
\end{tabular}

across the four recording units. Noteworthy, they were blinded to the genotype of the mice and were not involved in the EEG data analysis.

The two experts used the visual inspection (i.e., video of the mice) to classify recording epochs lasting $10 \mathrm{~s}$ into behavioral classes. The video was available for all mice in the Janssen, Lundbeck, and MNI units. Instead, the video was available for $80 \%$ of the mice in the UNIVR unit (i.e., the video of $20 \%$ of the UNIVR mice was unavailable for technical failures). In the UNIVR and Janssen units, the behavioral classification was also corroborated by additional variables such as body temperature, EMG activity recorded from neck muscles, and instrumental markers of the movement (i.e., actigraphy).

The mean discrepancy in the classification between two independent experts was less than $5 \%$ of the total $10 \mathrm{~s}$ epochs, thus confirming the success in the preliminary harmonization of the classification procedures within the recording units. The $10 \mathrm{~s}$ epochs receiving different behavioral classification were not considered in the subsequent spectral and statistical analyses.

The animal behavior was classified into "active" and "passive" conditions in wakefulness based on the following definitions:

(1) Active behavior (condition). Animals performed overt exploratory movements in the cage for most of the given epoch. The exploratory movements were characterized by ample displacements of body parts such as trunk, head, and forelimbs (when videos were available). They had not to be confounded with Instinctive activities (vide infra).

(2) Passive behavior (condition). Animals performed no (i.e., substantial immobility) or small movements of the trunk, head, and forelimbs. The maximal duration of immobility lasted $10 \mathrm{~s}$. The maximal duration of small movements of the trunk, head, and forelimbs lasted $10 \mathrm{~s}$. These criteria were expected to 
minimize the risk that "passive condition" be misclassified as sleep and vice-versa.

Particular attention was devoted to distinguishing the "active" and "passive" conditions as compared to other behavioral states based on the following definitions:

(1) Behavioral sleep state. Each epoch of the sleep state, as behaviorally defined, corresponded to immobility of the animals for the entire period of observation (inferred by visual analysis when videos were available) and during longer periods of immobility lasting several minutes with signs of muscle relaxation. As mentioned above, attention was devoted to avoiding misinterpretation of the passive condition and sleep state. The sleep condition was also denoted by the lowest values of body temperature and EMG activity as compared to the other behavioral states (UNIVR and Janssen units).

(2) Instinctive behavior. This behavioral class was detected when the animal showed movements such as cleaning, drinking, eating, etc. for most of the period (inferred by visual analysis when videos were available). The instinctive behavior was also denoted by increased body temperature and EMG activity as compared to passive behavior in wakefulness or sleep (UNIVR and Janssen units). As mentioned above, special attention was paid not to include these epochs in the active behavior epochs.

(3) Undefined. Each epoch classified as undefined showed a mix of the other behavioral classes or lack of clarity about the behavioral situation of the animal. Such epochs were excluded from the analysis.

According to PharmaCog guidelines, the experiment should not use EEG data to classify the epochs to avoid circular logic. Based on the above analysis of behavioral states, the first $5 \mathrm{~min}$ of artifact-free EEG epochs classified as the active condition were selected for the EEG data analysis. The same procedure of selection was followed by the epochs of the passive condition.

\section{EEG data analysis}

The behavioral epochs of the active and passive state were segmented off-line in consecutive epochs lasting $2 \mathrm{~s}$ each. The $2 \mathrm{~s}$ EEG epochs with muscle,
EEG, electrocardiographic (EKG), instrumental or other artifacts (no epileptic-like EEG activity) were excluded from the centralized EEG data analysis. In the WT mice group, the rejected EEG epochs were $1.19 \%( \pm 0.57$, SEM, standard error mean) for the active state and $1.90 \%( \pm 0.69$ SEM) for the passive state. In the TASTPM mice group, they were $7.77 \%$ $( \pm 0.41, \mathrm{SEM})$ for the active state and $11.12 \%( \pm 2.82$ SEM) for the passive state.

In the Janssen and UNIVR recording units, the EEG data were recorded with a bipolar electrode montage providing frontoparietal EEG signals. In the Lundbeck and MNI recording units, the EEG data were recorded with a monopolar electrode montage providing frontal and parietal EEG signals, separately. To have an identical montage for the group data analysis, EEG data of the Lundbeck and MNI recording units were re-referenced to obtain bipolar frontoparietal EEG signals. The re-referencing to that bipolar electrode montage was computed offline with a mathematical procedure consisting of the subtraction of the signal recorded by the monopolar parietal channel from the signal recorded by the frontal monopolar channel. The bipolar frontoparietal EEG signals were then inspected for the artefact rejection and used as an input for the subsequent statistical analysis.

\section{Spectral analysis of the EEG data}

The artefact-free frontoparietal bipolar EEG epochs of the active and passive condition were used as an input for the spectral EEG data analysis, namely the computation of EEG power (density). This analysis was performed by a standard (MATLAB; MathWorks, Natick, Massachusetts USA) FFT algorithm using Welch technique and Hanning windowing (no overlap of the time windows) function with $0.5 \mathrm{~Hz}$ frequency resolution. Normalization of the results of FFT analysis was obtained by computing the ratio between the absolute EEG power at each frequency bin and the absolute EEG power value averaged across all frequency bins $(0-100 \mathrm{~Hz}$, frequency bin of net currents not considered). After this normalization, the EEG power lost the original physical dimension and was represented by an arbitrary unit scale. In this line, for each mouse, the maximum value of normalized EEG power was equal to the ratio between the maximum value of absolute EEG power with the absolute EEG power value averaged across all frequency bins. For example, in a given mouse, if the maximum absolute EEG power 
at $3 \mathrm{~Hz}$ was $150 \mu \mathrm{V}^{2} / \mathrm{Hz}$ and the mean of the absolute EEG power across $0-100 \mathrm{~Hz}$ was $15 \mu \mathrm{V}^{2} / \mathrm{Hz}$, the normalized EEG power at $3 \mathrm{~Hz}$ was 10 .

Two frequency bins of interest named as individual delta and theta frequencies (IDF and ITF), respectively, were detected. In a given mouse, the IDF was defined as the frequency bin showing the highest amplitude of the normalized EEG power (density) between 1 and $6 \mathrm{~Hz}$ (delta frequency range) at the bipolar frontoparietal electrodes during the passive condition. Furthermore, the ITF was defined as the frequency bin showing the highest amplitude of the normalized EEG power density between 6.5 and $10 \mathrm{~Hz}$ (theta frequency range) at the bipolar frontoparietal electrodes during the exploratory active condition. The frequency and amplitude of the IDF and ITF peaks were considered as markers of the normalized EEG power during the passive and the active condition, respectively.

\section{Statistical analysis}

Four statistical sessions were performed by the commercial tool STATISTICA 10 (StatSoft Inc., http://www.statsoft.com) to test the primary hypotheses of the present study and make comparable the present findings with those of previous studies by our group applying the same methodology in WT [39] and PDAPP [40] mice. In all statistical sessions, those hypotheses were tested by ANOVAs $(p<0.05)$. In the first statistical session, the ANOVA used the frequency bin of IDF and ITF as the dependent variable. In the other statistical sessions, the ANOVAs used the normalized EEG power (density) of IDF and ITF as the dependent variable. Mauchly's test evaluated the sphericity assumption, and degrees of freedom were corrected by the Greenhouse-Geisser procedure when appropriate $(p<0.05)$. Finally, the Duncan test was used for post-hoc comparisons $(p<0.05)$, while significant results were controlled by the Grubbs test $(p<0.01)$ for the presence of outliers. For the sake of brevity, in the Supplementary Material, we reported confirmatory results of some control analyses using groups perfectly matched as ages and EEG power density at fixed frequency bands of interest $(p<0.05)$.

The first session evaluated the hypothesis that the IDF and ITF may slow in frequency in the TASTPM mice as compared to the WT littermates. Furthermore, we tested the reliability of those hypothesized differences between the two groups in the four EEG recording units. To address this hypothesis, the 3-way ANOVA used the frequency $(\mathrm{Hz})$ values showing the maximum normalized EEG power (density) value of IDF and ITF as the dependent variable. The ANOVA factors (independent variables) were Group (WT and TASTPM), Recording Unit (Janssen, Lundbeck, MNI, and UNIVR), and Frequency (IDF and ITF).

The second session evaluated the hypothesis that the IDF and ITF values may differently react to the passive and active conditions. Furthermore, we tested the reliability of those differences in the four EEG recording units. To address this hypothesis, the 3-way ANOVA used the normalized EEG power (density) of IDF and ITF values in the WT group as the dependent variable $(p<0.05)$. The ANOVA factors (independent variables) were Recording Unit (Janssen, Lundbeck, MNI, and UNIVR), Condition (active and passive), and Frequency (IDF and ITF). As compared to the second session, the third session used the same 3way ANOVA models and hypotheses in the TASTPM group $(p<0.05)$.

The fourth session evaluated the hypothesis that in comparison with the WT group, the TASTPM group showed smaller differences in the normalized EEG power (density) of IDF and ITF between the active versus passive conditions. To evaluate this hypothesis, a preliminary step was the computation of the difference in the normalized EEG power (density) between the two behavioral conditions (active minus passive) as the dependent variable of a 3-way ANOVA design. The ANOVA factors (independent variables) were Group (WT and TASTPM), Recording Unit (Janssen, Lundbeck, MNI, and UNIVR), and Frequency (IDF and ITF).

\section{RESULTS}

\section{Normalized EEG power (density) during active and passive conditions in WT and TASTPM mice}

Figure 1 shows the grand average of the EEG power (density) in the WT $(\mathrm{N}=58)$ and TASTPM $(\mathrm{N}=29)$ mice were characterized by differences in the EEG power (density) during the passive versus active conditions. Both groups of mice showed an EEG power peak at $1-6 \mathrm{~Hz}$ (i.e., delta range; IDF peak), greater in the passive than the active condition. Furthermore, there was another EEG power peak within the theta range (i.e., $6.5-10 \mathrm{~Hz}$; ITF peak), which was higher in the active than the passive condition. Moreover, there was a peak of the EEG power difference (active minus passive) at $1-6 \mathrm{~Hz}$, which reflected the higher values of the delta power in the passive than the active condition. Finally, there was a peak of the EEG power 


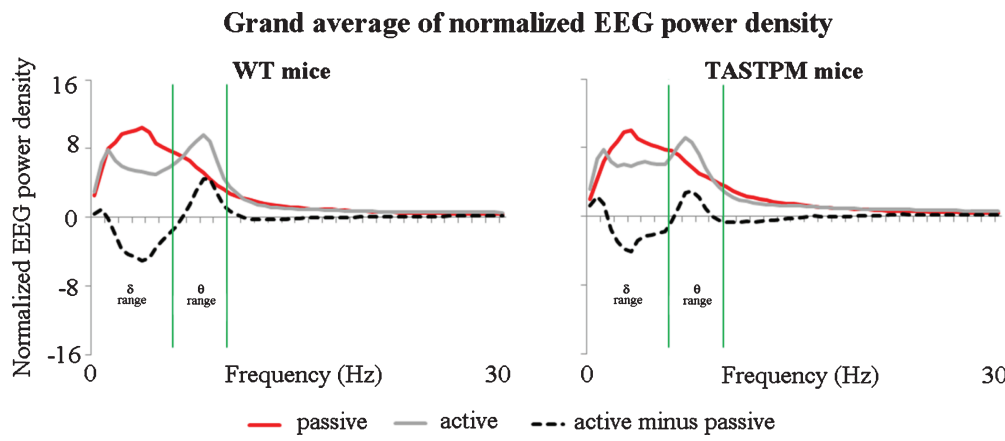

Fig. 1. Grand average of the normalized electroencephalographic (EEG) power (density) in the WT $(\mathrm{N}=58$, left) and TASTPM (N=29, right) mice. The graph represents the normalized EEG power (density) to the frequency range between 0 and $30 \mathrm{~Hz}$ at the bipolar fronto-parietal electrode for the passive and active condition during the dark phase of the day (note that mouse is a nocturnal animal). The difference of the normalized EEG power between the active and the passive condition (active minus passive) is also reported (dotted EEG power spectra).

difference at $6.5-10 \mathrm{~Hz}$, which reflected the higher values of the theta power in the active than in the passive condition.

Figure 2 reports the grand average of the EEG power in the WT and TASTPM groups at any recording unit considered separately. Concerning inter-center differences, we observed that the WT mice were characterized by similar EEG power waveforms in all recording units. Furthermore, the TASTPM mice were characterized by similar EEG power waveforms in all recording units: but one (i.e., UNIVR).

\section{Comparison of the frequency and normalized} EEG power between the WT and TASTPM group

Figure 3 (top) plots the distribution of the frequency bin $(\mathrm{Hz})$ of the IDF and ITF of the frontoparietal EEG activity recorded in the individual WT and TASTPM mice. Figure 3 (bottom) shows that distribution in the individual WT and TASTPM mice of any recording unit considered separately. No outlier was found (Grubbs test, $p<0.05$ ). The 3 -way (Group, Recording Unit, and Frequency) ANOVA showed no statistically significant results $(p>0.05)$, thus suggesting similar IDF and ITF values in the WT and TASTPM mice.

Figure 4 (top) illustrates the individual values of the frontoparietal normalized EEG power (density) for the WT (left) and TASTPM (right) mice at the two frequency peaks (IDF and ITF) and the two behavioral conditions (active, passive). Figure 4 (bottom) shows those individual values for the WT (left) and TASTPM (right) mice of any recording unit considered separately. Only one outlier was found in the WT group (Grubbs test, $p<0.05$ ).
The 3-way ANOVAs (Group, Recording Unit, and Frequency) in both groups (WT, TASTPM) showed a significant interaction Condition $\mathrm{X}$ Frequency $(\mathrm{F}=214.1, p<0.00001$ and $\mathrm{F}=74.2, p<0.00001$, respectively). Duncan post-hoc test indicated that this effect was due to the following significant differences: 1) IDF EEG power greater during the passive than the active condition $(p<0.000005$ in the WT group and $p<0.0001$ in the TASTPM group) and 2) ITF EEG power greater during the active than the passive condition $(p<0.00005$ in the WT group and $p<0.0001$ in the TASTPM group).

In the WT mice, the ANOVA showed a nonsignificant second-order interaction (Condition $\mathrm{X}$ Recording Unit X Frequency interaction, $p>0.05$ ), indicating similar effects in the four recording units. In those units, we computed the effect sizes (Cohen's d) with the following results: 3.32 (IDF power) and -1.29 (ITF power) for the Janssen unit, 2.33 (IDF power) and -1.77 (ITF power) for the Lundbeck unit, 2.65 (IDF power) and - 1.33 (ITF power) for the MNI unit, and 1.56 (IDF power) and -1.32 (ITF power) for the UNIVR unit, namely all ranging between large (1.20) and very large (2.0) effect sizes [42].

In the TASTPM mice, the ANOVA showed a significant second-order interaction Condition $\mathrm{X}$ Recording Unit X Frequency $(\mathrm{F}=11.8, p<0.0001)$. Duncan post-hoc test indicated that the TASTPM group was characterized by (1) IDF EEG power greater during the passive than the active condition in 3 out of 4 units (Janssen: $p<0.001$; Lundbeck: $p<0.001$; MNI: $p<0.005$ ) and (2) ITF EEG power greater during the active than the passive condition in only one unit (Lundbeck: $p<0.001$ ). These results may indicate a moderate reliability across the four units of the above effects in the TASTPM mice, since 


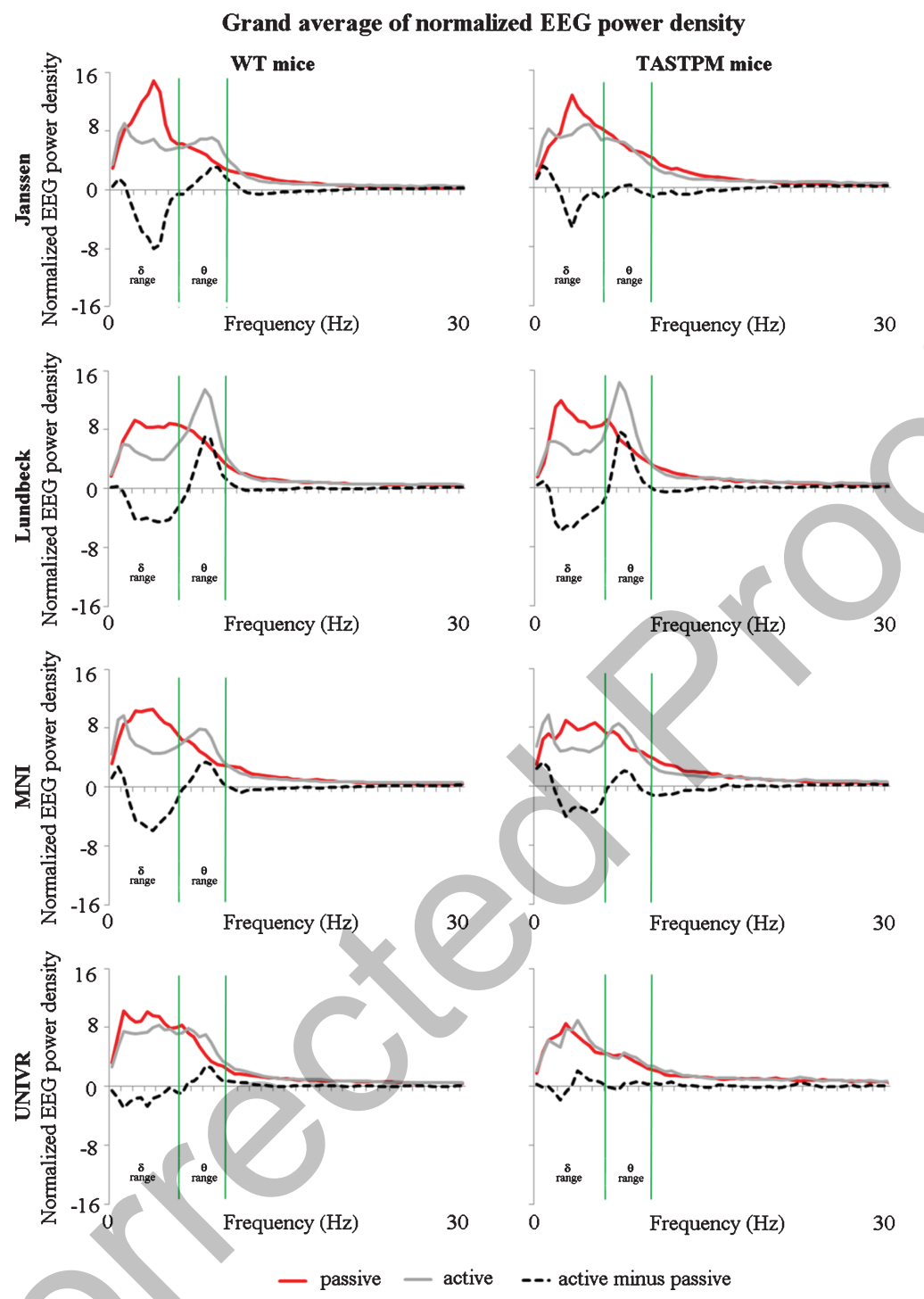

Fig. 2. Grand average of the normalized EEG power (density) in the WT and TASTPM mice of any recording unit considered separately (i.e., Janssen, Lundbeck, MNI, and UNIVR). The graph represents the normalized EEG power density to the frequency range between 0 and $30 \mathrm{~Hz}$ at the bipolar fronto-parietal electrode for the passive and active condition during the dark phase of the day. The difference of the normalized EEG power between the active and the passive condition (active minus passive) is also reported.

the UNIVR unit showed no statistical significance post-hoc differences in the IDF EEG power between the active and passive conditions. In the four units, we computed the effect sizes (Cohen's d) with the following results: 1.53 (IDF power) and -0.32 (ITF power) for the Janssen unit, 3.45 (IDF power) and -5.34 (ITF power) for the Lundbeck unit, 1.27 (IDF power) and -1.51 (ITF power) for the MNI unit, and 0.37 (IDF power) and -0.44 (ITF power) for the UNIVR unit, thus ranging between a small $(0.2$, Cohen, 1988$)$ and very large (2.0) effect sizes [42].
Figure 5 (top) displays the individual difference of the frontoparietal normalized EEG power (density) between the active and the passive condition (active minus passive) at the two frequency peaks (IDF, ITF) for the WT and TASTPM mice. Figure 5 (bottom) illustrates those individual differences for the WT and TASTPM mice of any recording unit considered separately. In the figure, IDF and ITF EEG power values at zero in those differences indicated the same frontoparietal normalized EEG power in the active and passive conditions, namely 


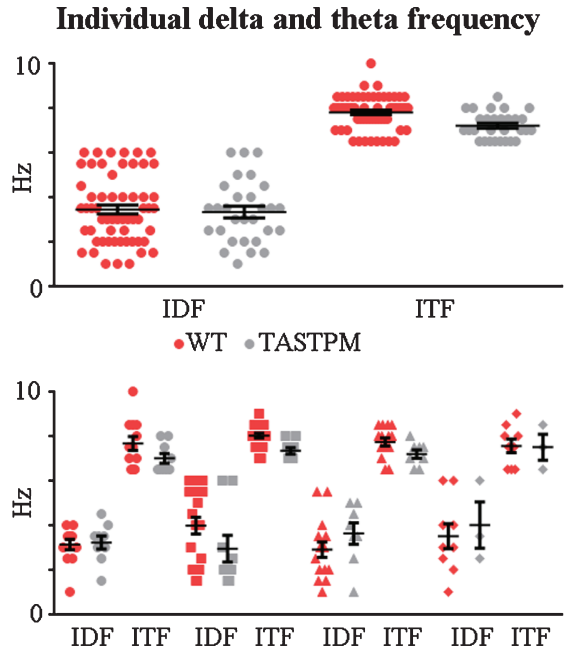

-WT Janssen • TASTPM Janssen • WT UNIVR • TASTPM UNIVR "WT Lundbeck «TASTPM Lundbeck $\triangle$ WT MNI $\triangle$ TASTPM MNI

Fig. 3. (Top): Individual values of delta and theta frequency (IDF and ITF, respectively) for the WT and TASTPM mice. The graph represents the individual frequency peaks within the delta $(1-6 \mathrm{~Hz}$; individual delta frequency, IDF) and the theta $(6-10 \mathrm{~Hz}$; individual theta frequency, ITF) frequency bands corresponding to the highest amplitude of the normalized EEG power (density) at the bipolar frontoparietal electrodes. (Bottom): IDF and ITF for the WT and TASTPM mice of any recording unit considered separately (i.e., Janssen, Lundbeck, MNI, and UNIVR).

showing no condition-dependent EEG reactivity. Positive (negative) IDF and ITF values in those differences indicated that that the EEG power was greater (lower) in the active than the passive condition, namely showing a condition-dependent EEG reactivity. No outlier was found (Grubbs test, $p<0.05$ ).

As reported in the Methods section, a 3-way (Group, Recording Unit, and Frequency) ANOVA design compared the difference of the normalized EEG power in the two conditions (active minus passive) between the TASTPM versus WT groups $(p<0.05)$. This ANOVA showed a significant interaction Group X Frequency $(\mathrm{F}=13.2, p<0.0005)$. Duncan post-hoc test unveiled less negative values in the active minus passive EEG power at the IDF in the TASTPM over the WT group $(p<0.0005)$, indicating a less condition-dependent reactivity of that EEG variable in the former than the latter group. Furthermore, the ANOVA showed a significant second-order interaction Group X Recording Unit X Frequency $(\mathrm{F}=4.3, p<0.01)$. Duncan post-hoc test indicated that such an effect at the IDF was observed in 3 out of 4 EEG recording units (Janssen: $p<0.0005$; MNI: $p<0.05$; UNIVR: $p<0.0005$ ), pointing to a moder- ate reliability across the units of the mentioned EEG results at delta frequencies.

Table 2 reports the results of all main statistical analyses.

\section{DISCUSSION}

Here we tested whether changes (reactivity) in ongoing cortical EEG rhythms accompanying the cage exploration (active condition) benchmarked with quiet wakefulness (passive condition) may be altered in TASTPM mice, characterized by AD-like accumulation in the cerebral $A \beta_{1-42}$ and cognitive deficits over aging $[35,36]$. We also tested the reproducibility of the present findings in 4 research centers of the PharmaCog study.

In this study, both TASTPM and control WT groups exhibited a significant reactivity in the frontoparietal normalized EEG power (density) during the mentioned active over the passive condition. Specifically, the active condition induced a reduction in delta power and an increase in theta power. This reactivity in ongoing delta and theta EEG rhythms may reflect neurophysiological oscillatory mechanisms underlying increased cortical arousal, vigilance, and maybe cognitive processes during the cage exploration. These results extend previous EEG evidence in rodents showing increased brain theta power during overt animal movements as compared to quiet wakefulness [22, 43-48].

As a main result of the present study, as compared to the WT mice, the TASTPM mice showed less reduction (condition-dependent EEG reactivity) in the frontoparietal normalized delta power during the cage exploration using the passive condition as a reference. This condition-dependent effect on cortical EEG rhythms was more evident using delta frequencies selected on an individual basis, but it was observed even with the use of fixed delta frequencies $(<4 \mathrm{~Hz})$ in all mice.

Concerning the reliability of this finding, 3 out of 4 PharmaCog recording units produced data showing the mentioned poor reactivity in frontoparietal delta rhythms in the TASTPM mice. This moderate variability of the EEG biomarker may be due to some intrinsic differences among centers such as animal colonies, animal management and handling during developmental age, electrodes (i.e., kind, material), electrode implantation procedures, EEG machines and electric contacts during recordings, cage features and general recording environments 


\section{Amplitude of normalized EEG power density at individual delta and theta frequency}
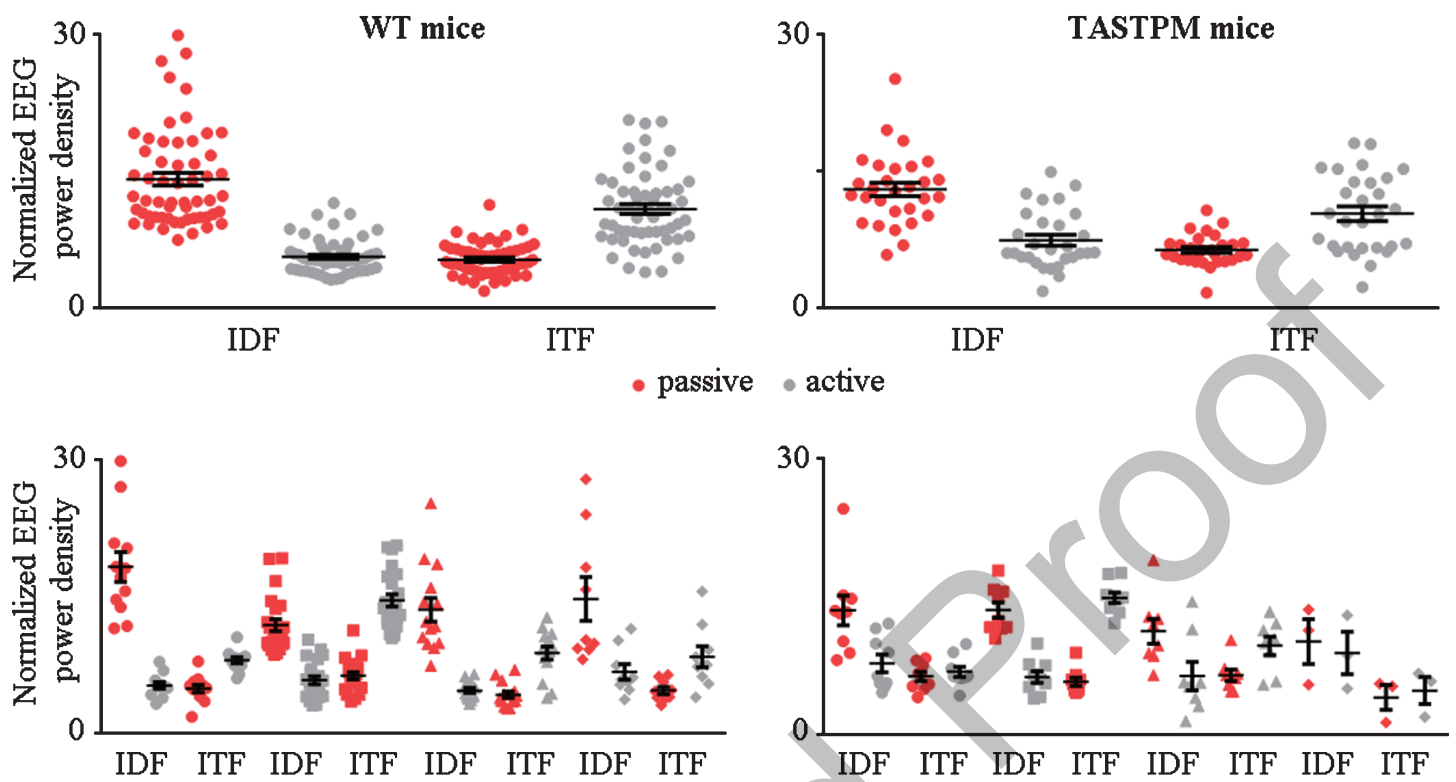

- passive Janssen - active Janssen $=$ passive Lundbeck $\approx$ active Lundbeck $\triangle$ passive MNI $\triangle$ active MNI • passive UNIVR • active UNIVR

Fig. 4. (Top): Individual values of the normalized EEG power for the WT (left) and TASTPM (right) mice. The frontoparietal normalized EEG power is represented for the two conditions (active and passive) and the two frequency peaks (IDF and ITF). (Bottom): Individual values of the normalized EEG power (density) for the WT (left) and TASTPM (right) mice of any recording unit considered separately (i.e., Janssen, Lundbeck, MNI, and UNIVR). The frontoparietal normalized EEG power is represented for the two conditions (active and passive) and the two frequency peaks (IDF and ITF). Asterisks indicate statistically significant differences between the active and the passive conditions at $p<0.05$.

(i.e., environmental noise), experimenters managing animals, animal healthiness and behavior during EEG recordings, etc. To mitigate at least some sources of variability (i.e., electrode materials, EEG machines, and environmental noise across the four recording units), we implemented the following procedures: 1) the computation of EEG power (density) in a frontoparietal electrode montage; 2 ) the normalization in frontoparietal EEG power across all frequencies from 1 to $100 \mathrm{~Hz}$ in any EEG individual dataset; and 3) the use of standard open-field cages with no toys, running wheels for motor activity, or other uncontrolled sources of external stimuli. However, the results of the present study indicate that other sources of variability (e.g., materials, procedures, and animals) may affect the present EEG biomarkers at the level of single recording units. Therefore, a reasonable option to counteract this variability may be the use of designs with multiple $(\mathrm{N}=3$ or 4$)$ EEG recording units.

In TASTPM mice, the poor condition-dependent EEG reactivity in the frontoparietal normalized delta power may be related to some AD-like abnormalities in the brain and behavior. Previous studies have shown that at the age of 6-24 months, TASTPM mice are characterized by relevant $\mathrm{AD}$ manifestations such as cognitive deficits and $A \beta$ deposition with dystrophic neurites in the cerebral cortex, hippocampus, and thalamus $[35,36]$. Furthermore, in TASTPM mice, brain amyloidosis was related to hypometabolism, neuroinflammation, and neurodegeneration across the cerebral cortex, hippocampus, basal ganglia, and thalamus [49]. Of note, these regions are important nodes of neural networks regulating ongoing EEG rhythms and brain arousal in wakefulness [50-54]. Taking together the previous and the present data, we speculate that in TASTPM mice, the poor reactivity in frontoparietal normalized delta power $(<4 \mathrm{~Hz})$ during the cage exploration may reflect the effects of $\mathrm{AD}$ neuropathology on thalamus-cortical neurophysiological mechanisms underpinning cortical arousal, vigilance, and maybe cognitive-motor functions. 
Amplitude of normalized EEG power density at individual delta and theta frequency
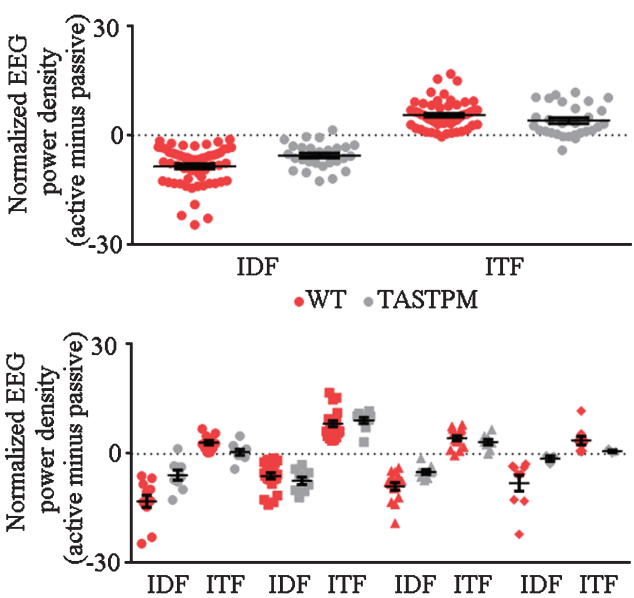

-WT Janssen - TASTPM Janssen • WT UNIVR •TASTPM UNIVR "WT Lundbeck "TASTPM Lundbeck $\triangle$ WT MNI $\triangle$ TASTPM MNI

Fig. 5. (Top): Individual values of the difference of the normalized EEG power between the active and the passive condition (active minus passive) at the two frequency peaks (IDF and ITF) for the WT and TASTPM mice. (Bottom): Individual values of the difference of the normalized EEG power (density) between the active and the passive condition (active minus passive) at the two frequency peaks (IDF and ITF) for the WT and TASTPM mice of any recording unit considered separately (i.e., Janssen, Lundbeck, MNI, and UNIVR). Asterisks indicate statistically significant differences between the WT and the TASTPM groups at $p<0.05$.

In the present study, we reported a negative outcome, namely the lack of significant abnormalities at frontoparietal theta rhythms in the TASTPM mice in contrast to those reported in the PDAPP mice in the study by [40]. TASTPM mice have a Swedish double mutation in human $A P P$, tangles are absent, and neural loss is relatively mild, appearing only at 10 months of age $[35,36]$. In the present study, the TASTPM mice were 13-month old on average. In contrast, PDAPP mice overexpress human APP Indiana V717F. They typically develop not only cortical, corpus callosum, and hippocampus $A \beta$ deposits/plaques from about 6-9 months of age [55, 56] but also phosphorylated tau immunoreactivity in dystrophic neurites from 14 months of age [57]. In a previous study [40], the PDAPP mice were 23 months old on average. Keeping in mind these data, it can be speculated that as compared to the PDAPP mice of the previous study [40], the present TASTPM mice might not show EEG abnormalities in theta rhythms due to a younger age and the kind of APP mutation. Future experiments should investigate the correlation between age-related changes in condition-dependent EEG reactivity and relevant neuropathological, metabolic, and behavioral effects of APP and PS1 mutations in those AD mouse models. Results may support the preference of one over the other mouse model of AD for multicentric EEG studies.

The present results also complement and extend those of the following bulk of previous studies in mice: 1) mice with mutations in the APP gene showed abnormal ongoing brain EEG rhythms [44]; 2) mice carrying mutated human $A P P$ Swedish and $P S 1$ genes showing fibrillogenic $A \beta_{1-42}$ and amyloid plaques exhibited reduced cortical theta (absolute) power and enhanced beta and gamma (absolute) power in wakefulness, but these changes did not dependent on $A \beta_{1-42}$ deposits as they did not progress over aging from 9 months of age [58]. These mice also showed reduced cortical theta (absolute) power and enhanced beta and gamma (absolute) power in wakefulness, but these changes did not dependent on $A \beta_{1-42}$ deposits as they did not progress over aging [58]. Furthermore, APP but not PS1 single mutant mice had similar alterations in theta, beta, and gamma power, while APP/PS1 (but not APP single-mutant) mice had high insoluble $A \beta_{1-42 / 40}$ levels and core brain amyloid plaques at 13 months of age [58]; 3) APP Swedish and PS1 mutant mice showed increased brain EEG (absolute) power at a large frequency band beyond delta rhythms [45, 46]; 4) the second generation of $\mathrm{AD}$ mouse models as triple transgenic mice (i.e., triple transgenic mice express low levels of mutant human $A P P$, tau, and presenilin-1) presented abnormal ongoing EEG rhythms [59-61]; 5) the same was true in humanized mice (i.e., humanized mice contain functional human cells or tissues [62-65]; 6) triple transgenic mice (i.e., $3 \times \mathrm{Tg}$ and PLB1 triple) over controls were characterized by a decrease of theta power during wakefulness or cognitive tasks $[60,61]$ and an increase of delta power during wakefulness and REM sleep [59]; 7) tripletransgenic $\mathrm{AD}$ mice challenged with the potassium channel blocker 4-aminopyridine had reduced theta amplitude compared with 4-aminopyridine-treated control mice [61]; 8) in rodents, abnormalities of delta power were related to impairments in long-term and short-term hippocampal plasticity and cognitive deficits in recognition memory and spatial learning [59]; 9) compared to mice humanized to apolipoprotein $A P O E 3$, mice humanized to APOE4 showed abnormal beta activity during olfactory tasks [64]; 9) in transgenic mice, the activation of basal forebrain cholinergic neurons, traced by humanized Renilla 
green fluorescent protein (hrGFP), significantly and lastingly decreased the EEG delta power spectrum, produced low-delta non-rapid eye movement sleep, and slightly increased wakefulness, whereas the inhibition of basal forebrain cholinergic neurons significantly increased EEG delta power spectrum and slightly decreased wakefulness [65].

Keeping in mind these previous data (including those in PDAPP mice), it can be speculated that in TASTPM mice, mutations in APP and relative circulating $A \beta$ species may play a major role in inducing the present condition-dependent poor reactivity in frontoparietal normalized delta power and a general increase in absolute EEG power at theta, alpha, and beta frequencies. This effect may be possibly related to an over-excitability induced by these $A \beta$ species in hippocampal and thalamus-cortical functional networks regulating cortical arousal in wakefulness.

A significant effect of cerebral amyloid plaques on the present EEG markers cannot be excluded. In TASTPM mice, object recognition deficits can be observed when the amyloid deposits with fibrillar plaques become evident at the hippocampal and cortical level, which occurs at approximately six months of age [36, 37]. However, it should be remarked that in PDAPP mice, cognitive deficits can be observed before brain plaque deposition, which occurs at approximately six months of age $[55,66]$. Future studies in behaving TASTPM mice may test the hypothesis about relationships among brain amyloid plaque deposition, the manifestation of cortical and thalamic epileptiform EEG activity, and the poor behavioral condition-dependent reactivity in frontoparietal normalized delta power.

At the present early stage of the research, a neuropathophysiological interpretation of similarities and differences in ongoing EEG rhythms recorded in AD patients and TASTPM mice is premature. Therefore, we just summarize emerging features of those EEG activities in the following. In healthy cognitively unimpaired adults, resting state eyesclosed condition is associated with alpha rhythms $(8-12 \mathrm{~Hz})$ dominating in posterior areas of cerebral cortex, as a reflection of sensory deprivation, muscle relaxation, and low cortical arousal and vigilance [66-68]. These rhythms decrease in power during perceptual, memory, and motor demands, as a reflection of increased cortical arousal, vigilance, and higher cognitive processes [67-72]. As compared to Nold subjects, AD patients were characterized by lower power in posterior alpha rhythms in the resting state eyes-closed condition and lower reac- tivity in these rhythms after the eyes opening $[11,18$, 73-77], possibly reflecting poor cholinergic modulation of related to changes in vigilance [23, 72]. In relation to those literature data, the TASTPM mice of the present study showed different features of condition-dependent ongoing cortical EEG rhythms. In the EEG power density spectra, they exhibited neither a power peak in the alpha range $(8-12 \mathrm{~Hz})$ during the quiet wakefulness (i.e., passive condition) nor the reduction in this power peak during the cage exploration (i.e., active condition). In the experimental condition with freely behaving TASTPM mice, poor reactivity in cortical delta rhythms during exploratory movements might reflect not only poor changes in vigilance but also abnormal visuospatial navigation, memory, and sensorimotor integration [55].

\section{Methodological limitations of the study}

The present results should be just considered as an exploratory study due to the following methodological limitations of the study.

Firstly, the small number $(\mathrm{N}=3)$ of TASTPM mice of the UNIVR unit was a significant limitation of the present study and did not permit conclusive and definitive EEG results of that unit.

Secondly, the present experimental procedures did not permit a translational understanding of the neurophysiological mechanisms modulating cortical arousal in physiological and pathological (e.g., AD neuropathology) conditions. In physiological conditions, human resting state EEG rhythms reflect the cortical arousal due to visual processes induced by the eyes opening (i.e., active condition) and the effects on vigilance. In contrast, those of the present experiments reflected visuo-spatial, memory, and somatomotor integrating processes related to the exploration of the cage (i.e., active condition). In $\mathrm{AD}$ patients, the brain is affected not only by the accumulation of $A \beta_{1-42}$ but also by tauopathy and often a certain degree of cerebrovascular disease.

Thirdly, the different dominant frequencies of cortical EEG rhythms between mice and humans might be partially provoked by the head as a volume conductor. Mice are typically characterized by prominent theta rhythms mainly generated in the hippocampus and surrounding structures about exploratory behaviors. In the small mouse brain, hippocampal theta activity might propagate to near electrodes located in the parietal cortex. As a consequence, changes in ongoing theta rhythms at those cortical electrodes 
(especially in the parietal cortex) might be partially affected by hippocampal oscillatory neural currents produced at theta frequencies during exploratory movements [78, 79].

Fourthly, the mouse behavior was qualitatively rated as active versus passive based on a harmonized visual rating protocol in the four research units of this study. In that protocol, movement velocity and extension were not considered. Therefore, the reported EEG differences in the two mouse groups (i.e., WT and TASTPM) might partially depend on different quantitative motor features in the active condition. This limitation is relevant as hippocampal theta rhythms might reflect some features of movements [49, 80, 81].

Fifthly, it can be argued that confounding microsleeps may affect one the main results of the present study, namely the decreased difference in the normalized EEG power (active minus passive behavioral mode) at the individual delta frequency (IDF) in the TASTPM as compared to the control (WT group). Indeed, the use of $10 \mathrm{~s}$ epochs for the determination of the behavioral mode could not prevent that short microsleeps (i.e., lasting few s) might be erroneously included in the passive-mode condition, especially in TASTPM mice suffering from AD neuropathology. In this regard, we do not think that the present results are substantially affected by microsleeps occurring during passive-mode periods. During these periods, microsleeps are expected to increase EEG power at delta frequencies. Therefore, results would have shown greater differences in IDF power between active minus passive modes in TASTPM over WT mice, exactly the opposite of the present findings. To exclude this confounding effect experimentally, future studies should crossvalidate the present results by a fine analysis of EEG, electrooculographic, and electromyographic data collected in passive-mode periods to identify and investigate microsleeps. Indeed, to our knowledge, the presence and EEG characteristics of microsleeps in mice were not previously explored.

Sixthly, we reported a moderate reliability of the present EEG markers across the four preclinical units and unveiled pros and cons useful for planning future academic and industrial EEG studies in TASTPM mice. This moderate reliability gave rise to the following questions. What (i.e., multisectoral or just industrial or academic?) and how many preclinical units should future consortia involve in multicenter EEG studies carried out in TASTPM mice to test inter-laboratory reliability of the results? What optimal reliability threshold should they use to accept or reject experimental results? The same questions may be relevant in other mouse models of $\mathrm{AD}$, and more research is needed to find out answers supporting future decision making, research, and applications.

Seventhly, the present study used ANOVAs to test the working hypotheses, in methodological line with previous EEG studies in WT and PDAPP mice carried out in the PharmaCog project $[39,40]$. This choice allowed the full comparability of the results across those previous studies and the present one. Noteworthy, the results of the present study motivate a future investigation including more WT and TASTPM mice and more than one EEG recording for each mouse to use linear mixed models and give more robustness to the observed 2- and 3-way interactions among the Group (WT and TASTPM), Frequency (IDF and ITF), and Recording Unit (the preclinical recording units in a multicentric study) factors.

As a final consideration, the current methodology cannot substitute other classical neurophysiological methodologies applied in mice, namely long EEG recordings investigating wake-cycle sleep, the experimental inoculation of stress or anxiety, and new technologies of virtual reality to simulate spatial navigation in animals during EEG recordings.

\section{Conclusions}

In the present study of the PharmaCog project (http://www.pharmacog.org), we tested the novel hypothesis of an abnormal behavioral conditiondependent reactivity in cortical EEG rhythms recorded in TASTPM mice. Furthermore, we evaluated the reliability of the experimental results in four recording units of the PharmaCog study.

As compared to the WT group, the TASTPM group showed lower reduction (reactivity) in the frontoparietal normalized delta power during the cage exploration over the quiet wakefulness. This effect was observed in 3 out of 4 PharmaCog recording units, so unveiling a moderate reliability of this EEG biomarker.

The present results cross-validate the same EEG effect observed in PDAPP mice in a previous study of the PharmaCog project [40]. Keeping in mind those previous and the present results, it can be speculated that the poor behavioral condition-dependent reactivity in cortical delta rhythms may be related to the effects of $A P P$ mutation and may reflect relevant 
aspects of $\mathrm{AD}$-like neuropathology and cognitive deficits.

Concerning the moderate reliability of the EEG biomarker, the present results unveiled pros and cons of multicenter EEG preclinical trials in TASTPM mice for future applications.

Future studies will have to cross-validate the present findings improving the classification of behavioral states (modes) of mice with quantitative approaches based on fine physiological and kinematic control parameters and learning machine classifiers.

\section{ACKNOWLEDGMENTS}

The activity leading to the present study has received funding from the European Community's Seventh Framework Programme (FP7/2007-2013) for the Innovative Medicine Initiative under Grant Agreement No. 115009 (Prediction of cognitive properties of new drug candidates for neurodegenerative diseases in early clinical development, PharmaCog). For further information on the PharmaCog project, please refer to http://www.pharmacog.org.

Some of the authors of the present article changed their affiliations during or after the PharmaCog project. In this article, we report their affiliations at the time of their scientific activities for the development of the present study of the PharmaCog project.

The PharmaCog project was a precompetitive public-private initiative of European Commission, and the present study included no administration of drugs in mice for the treatment of Alzheimer's disease. Therefore, we declare that the Authors belonging to Pharmaceutical companies had no relevant conflict of interest in the development of the present study.

In this study, the electroencephalographic data analysis was partially supported by the funds of "Ricerca Corrente" attributed by Italian Ministry of Health to the IRCCS SDN of Naples, IRCCS OASI of Troina, and IRCCS San Raffaele Pisana of Rome.

Authors' disclosures available online (https:// www.j-alz.com/manuscript-disclosures/19-0351r4).

\section{SUPPLEMENTARY MATERIAL}

The supplementary material is available in the electronic version of this article: https://dx.doi.org/ 10.3233/JAD-190351.

\section{REFERENCES}

[1] Braak H, Braak E (1995) Staging of Alzheimer's diseaserelated neurofibrillary changes. Neurobiol Aging 16, 271278.

[2] Bastos Leite AJ, Scheltens P, Barkhof F (2004) Pathological aging of the brain: An overview. Top Magn Reson Imaging 15, 369-389.

[3] Glodzik-Sobanska L, Rusinek H, Mosconi L, Li Y, Zhan J, de Santi S, Convit A, Rich K, Brys M, de Leon MJ (2005) The role of quantitative structural imaging in the early diagnosis of Alzheimer's disease. Neuroimaging Clin N Am 15, 803-826

[4] Dubois B, Feldman HH, Jacova C, Hampel H, Molinuevo JL, Blennow K, DeKosky ST, Gauthier S, Selkoe D, Bateman R, Cappa S, Crutch S, Engelborghs S, Frisoni GB, Fox NC, Galasko D, Habert MO, Jicha GA, Nordberg A, Pasquier F, Rabinovici G, Robert P, Rowe C, Salloway S, Sarazin M, Epelbaum S, de Souza LC, Vellas B, Visser PJ, Schneider L, Stern Y, Scheltens P, Cummings JL (2014) Advancing research diagnostic criteria for Alzheimer's disease: The IWG-2 criteria. Lancet Neurol 13, 614-629.

[5] Jeong J (2004) EEG dynamics in patients with Alzheimer's disease. Clin Neurophysiol 115, 1490-1505.

[6] Niedermayer E, Lopes da Silva FH (2005) Electroencephalography: Basic Principles, Clinical Applications, And Related Fields. 5th. Wolters Kluwer.

[7] Pfurtscheller G, Lopes da Silva FH (1999) Event-related EEG/MEG synchronization and desynchronization: Basic principles. Clin Neurophysiol 110, 1842-1857.

[8] Dierks T, Jelic V, Pascual-Marqui RD, Wahlund L, Julin P, Linden DE, Maurer K, Winblad B, Nordberg A (2000) Spatial pattern of cerebral glucose metabolism (PET) correlates with localization of intracerebral EEG-generators in Alzheimer's disease. Clin Neurophysiol 111, 1817-1824.

[9] Huang C, Wahlund L, Dierks T, Julin P, Winblad B, Jelic V (2000) Discrimination of Alzheimer's disease and mild cognitive impairment by equivalent EEG sources: A crosssectional and longitudinal study. Clin Neurophysiol 111, 1961-1967.

[10] Ponomareva NV, Selesneva ND, and Jarikov GA (2003) EEG alterations in subjects at high familial risk for Alzheimer's disease. Neuropsychobiology 48, 152-159.

[11] Babiloni C, Lizio R, Marzano N, Capotosto P, Soricelli A, Triggiani AI, Cordone S, Gesualdo, Del Percio C (2016) Brain neural synchronization and functional coupling in Alzheimer's disease as revealed by resting state EEG rhythms. Int J Psychophysiol 103, 88-102.

[12] Babiloni C, Benussi L, Binetti G, Bosco P, Busonero G, Cesaretti S, Dal Forno G, Del Percio C, Ferri R, Frisoni G, Ghidoni R, Rodriguez G, Squitti R, Rossini PM (2006) Genotype (cystatin C) and EEG phenotype in Alzheimer disease and mild cognitive impairment: A multicentric study. Neuroimage 29, 948-964.

[13] Babiloni C, Cassetta E, Binetti G, Tombini M, Del Percio C, Ferreri F, Ferri R, Frisoni G, Lanuzza B, Nobili F, Parisi L, Rodriguez G, Frigerio L, Gurzi M, Prestia A, Vernieri F, Eusebi F, Rossini PM (2007) Resting EEG sources correlate with attentional span in mild cognitive impairment and Alzheimer's disease. Eur J Neurosci 25, 3742-3757.

[14] Babiloni C, Frisoni GB, Pievani M, Vecchio F, Lizio R, Buttiglione M, Geroldi C, Fracassi C, Eusebi F, Ferri R, Rossini PM (2009) Hippocampal volume and cortical sources of EEG alpha rhythms in mild cognitive impairment and Alzheimer disease. Neuroimage 44, 123-135. 
[15] Stam CJ, Jelles B, Achtereekte HA, van Birgelen JH, Slaets JP (1996) Diagnostic usefulness of linear and nonlinear quantitative EEG analysis in Alzheimer's disease. Clin Electroencephalogr 27, 69-77.

[16] Stevens A, Kircher T (1998) Cognitive decline unlike normal aging is associated with alterations of EEG temporospatial characteristics. Eur Arch Psychiatry Clin Neurosci 248, 259-266.

[17] van der Hiele K, Vein AA, van der Welle A, van der Grond J, Westendorp RG, Bollen EL, van Buchem MA, van Dijk JG, Middelkoop HA (2007) EEG and MRI correlates of mild cognitive impairment and Alzheimer's disease. Neurobiol Aging 28, 1322-1329.

[18] Babiloni C, Lizio R, Vecchio F, Frisoni GB, Pievani M, Geroldi C, Claudia F, Ferri R, Lanuzza B, Rossini PM (2010) Reactivity of cortical alpha rhythms to eye opening in mild cognitive impairment and Alzheimer's disease: An EEG study. J Alzheimers Dis 22, 1047-1064.

[19] van der Hiele K, Bollen EL, Vein AA, Reijntjes RH, Westendorp RG, van Buchem MA, Middelkoop HA, van Dijk JG (2008) EEG markers of future cognitive performance in the elderly. $J$ Clin Neurophysiol 25, 83-89.

[20] Berendse HW, Verbunt JP, Scheltens P, van Dijk BW, Jonkman EJ (2000) Magnetoencephalographic analysis of cortical activity in Alzheimer's disease: A pilot study. Clin Neurophysiol 111, 604-612.

[21] Kurimoto R, Ishii R, Canuet L, Ikezawa K, Azechi M, Iwase M, Yoshida T, Kazui H, Yoshimine T, Takeda M (2008) Event-related synchronization of alpha activity in early Alzheimer's disease and mild cognitive impairment: An MEG study combining beamformer and group comparison. Neurosci Lett 443, 86-89.

[22] Vyazovskiy VV, Kopp C, Bösch G, Tobler I (2005) The GABAA receptor agonist THIP alters the EEG in waking and sleep of mice. Neuropharmacology 48, 617-626.

[23] Wan L, Huang H, Schwab N, Tanner J, Rajan A, Lam NB, Zaborszky L, Li CR, Price CC, Ding M (2019) From eyes-closed to eyes-open: Role of cholinergic projections in EC-to-EO alpha reactivity revealed by combining EEG and MRI. Hum Brain Mapp 40, 566-577.

[24] Palop JJ, Chin J, Roberson ED, Wang J, Thwin MT, Bien-Ly N, Yoo J, Ho KO, Yu GQ, Kreitzer A, Finkbeiner S, Noebels JL, Mucke L (2007) Aberrant excitatory neuronal activity and compensatory remodeling of inhibitory hippocampal circuits in mouse models of Alzheimer's disease. Neuron $\mathbf{5 5}$, 697-711.

[25] Westmark CJ, Westmark PR, Beard AM, Hildebrandt SM, Malter JS (2008) Seizure susceptibility and mortality in mice that over-express amyloid precursor protein. Int J Clin Exp Pathol 1, 157-168.

[26] Minkeviciene R, Rheims S, Dobszay MB, Zilberter M, Hartikainen J, Fülöp L, Penke B, Zilberter Y, Harkany T, Pitkänen A, Tanila H (2009) Amyloid beta-induced neuronal hyperexcitability triggers progressive epilepsy. $J$ Neurosci 29, 3453-3462.

[27] Ziyatdinova S, Gurevicius K, Kutchiashvili N, Bolkvadze T, Nissinen J, Tanila H, Pitkänen A (2011) Spontaneous epileptiform discharges in a mouse model of Alzheimer's disease are suppressed by antiepileptic drugs that block sodium channels. Epilepsy Res 94, 75-85.

[28] Sanchez A, Tripathy D, Yin X, Desobry K, Martinez J, Riley J, Gay D, Luo J, Grammas P (2012) p38 MAPK: A mediator of hypoxia-induced cerebrovascular inflammation. $J$ Alzheimers Dis 32, 587-597.
[29] Verret L, Krezymon A, Halley H, Trouche S, Zerwas M, Lazouret M, Lassalle JM, Rampon C (2013) Transient enriched housing before amyloidosis onset sustains cognitive improvement in Tg2576 mice. Neurobiol Aging 34, 211-225.

[30] Corbett BF, Leiser SC, Ling HP, Nagy R, Breysse N, Zhang X, Hazra A, Brown JT, Randall AD, Wood A, Pangalos MN, Reinhart PH, Chin J (2013) Sodium channel cleavage is associated with aberrant neuronal activity and cognitive deficits in a mouse model of Alzheimer's disease. J Neurosci 33, 7020-7026.

[31] Schneider F, Baldauf K, Wetzel W, Reymann KG (2014) Behavioral and EEG changes in male 5xFAD mice. Physiol Behav 135, 25-33.

[32] Born HA, Kim JY, Savjani RR, Das P, Dabaghian YA, Guo Q, Yoo JW, Schuler DR, Cirrito JR, Zheng H, Golde TE, Noebels JL, Jankowsky JL (2014) Genetic suppression of transgenic APP rescues. Hypersynchronous network activity in a mouse model of Alzheimer's disease. J Neurosci 34, 3826-3840.

[33] Rabinowicz AL, Starkstein SE, Leiguarda RC, Coleman AE (2000) Transient epileptic amnesia in dementia: A treatable unrecognized cause of episodic amnestic wandering. Alzheimer Dis Assoc Disord 14, 231-233.

[34] Palop JJ, Mucke L (2009) Epilepsy and cognitive impairments in Alzheimer disease. Arch Neurol 66, 435-440.

[35] Howlett DR, Richardson JC, Austin A, Parsons AA, Bate ST, Davies DC, Gonzalez MI (2004) Cognitive correlates of Abeta deposition in male and female mice bearing amyloid precursor protein and presenilin-1 mutant transgenes. Brain Res 1017, 130-136.

[36] Howlett DR, Bowler K, Soden PE, Riddell D, Davis JB, Richardson JC, Burbidge SA, Gonzalez MI, Irving EA, Lawman A, Miglio G, Dawson EL, Howlett ER, Hussain I (2008) Abeta deposition and related pathology in an APP x PS1 transgenic mouse model of Alzheimer's disease. Histol Histopathol 23, 67-76.

[37] Galluzzi S, Marizzoni M, Babiloni C, Albani D, Antelmi L, Bagnoli C, Bartres-Faz D, Cordone S, Didic M, Farotti L, Fiedler U, Forloni G, Girtler N, Hensch T, Jovicich J, Leeuwis A, Marra C, Molinuevo JL, Nobili F, Pariente J, Parnetti L, Payoux P, Del Percio C, Ranjeva JP, Rolandi E, Rossini PM, Schönknecht P, Soricelli A, Tsolaki M, Visser PJ, Wiltfang J, Richardson JC, Bordet R, Blin O, Frisoni GB; PharmaCog Consortium (2016) Clinical and biomarker profiling of prodromal Alzheimer's disease in workpackage 5 of the Innovative Medicines Initiative PharmaCog project: A 'European ADNI study'. J Intern Med 279, 576-591.

[38] Jovicich J, Babiloni C, Ferrari C, Marizzoni M, Moretti DV, Del Percio C, Lizio R, Lopez S, Galluzzi S, Albani D, Cavaliere L, Minati L, Didic M, Fiedler U, Forloni G, Hensch T, Molinuevo JL, Bartrés Faz D, Nobili F, Orlandi D, Parnetti L, Farotti L, Costa C, Payoux P, Rossini PM, Marra C, Schönknecht P, Soricelli A, Noce G, Salvatore M, Tsolaki M, Visser PJ, Richardson JC, Wiltfang J, Bordet R, Blin O, Frisoni GB (2018) Two-year longitudinal monitoring of amnestic mild cognitive impairment patients with prodromal Alzheimer's disease using topographical biomarkers derived from functional magnetic resonance imaging and electroencephalographic activity. $J$ Alzheimers Dis 69, 1535 .

[39] Del Percio C, Drinkenburg W, Lopez S, Infarinato F, Bastlund JF, Laursen B, Pedersen JT, Christensen DZ, Forloni G, Frasca A, Noè FM, Bentivoglio M, Fabene PF, Bertini G, Colavito V, Kelley J, Dix S, Richardson JC, 
Babiloni C; PharmaCog Consortium (2017) Ongoing electroencephalographic rhythms related to cortical arousal in wild type mice: The effect of aging. Neurobiol Aging 49, 20-30.

[40] Del Percio C, Drinkenburg W, Lopez S, Limatola C, Bastlund JF, Christensen DZ, Pedersen JT, Forloni G, Frasca A, Noè FM, Bentivoglio M, Fabene PF, Bertini G, Colavito V, Dix S, Ferri R, Bordet R, Richardso JC, Babiloni C (2018) Ongoing electroencephalographic activity associated with cortical arousal in transgenic PDAPP mice (hAPP v717f). Curr Alzheimer Res 15, 259-272.

[41] Franklin KBJ, Paxinos G (1997) The Mouse Brain in Stereotaxic Coordinates. Academic Press, San Diego.

[42] Sawilowsky S (2009) New Effect Size Rules of Thumb. Journal of Modern Applied Statistical Methods: Vol. 8, Iss. 2.

[43] Ziyatdinova S, Viswanathan J, Hiltunen M, Tanila H, Pitkänen A (2015) Reduction of epileptiform activity by valproic acid in a mouse model of Alzheimer's disease is not long-lasting after treatment discontinuation. Epilepsy Res 112, 43-55.

[44] Ziyatdinova S, Rönnbäck A, Gurevicius K, Miszczuk D, Graff C, Winblad B, Pitkänen A, Tanila H (2016) Increased epileptiform EEG activity and decreased seizure threshold in arctic APP transgenic mouse model of Alzheimer's disease. Curr Alzheimer Res 13, 817-830.

[45] Gurevicius K, Lipponen A, Tanila H (2013) Increased cortical and thalamic excitability in freely moving APPswe/PS1dE9 mice modeling epileptic activity associated with Alzheimer's disease. Cereb Cortex 23, 1148-1158.

[46] Jin N, Lipponen A, Koivisto H, Gurevicius K, Tanila H (2018) Increased cortical beta power and spike-wave discharges in middle-aged APP/PS1 mice. Neurobiol Aging 71, 127-141.

[47] Bland BH (1986) The physiology and pharmacology of hippocampal formation theta rhythms. Prog Neurobiol 26, $1-54$.

[48] Orzel-Gryglewska J, Matulewicz P, Jurkowlaniec E (2014) Theta activity in local field potential of the ventral tegmental area in sleeping and waking rats. Behav Brain Res $\mathbf{2 6 5}, 84-$ 92.

[49] Micotti E, Paladini A, Balducci C, Tolomeo D, Frasca A, Marizzoni M, Filibian M, Caroli A, Valbusa G, Dix S, O'Neill M, Ozmen L, Czech C, Richardson JC, Frisoni GB, Forloni G (2015) Striatum and entorhinal cortex atrophy in AD mouse models: MRI comprehensive analysis. Neurobiol Aging 36, 776-788

[50] Lörincz ML, Geall F, Bao Y, Crunelli V, Hughes SW (2009) ATP-dependent infra-slow $(<0.1 \mathrm{~Hz})$ oscillations in thalamic networks. PLoS One 4, e4447.

[51] Crunelli V, David F, Lôrincz ML, Hughes SW (2015) The thalamocortical network as a single slow wave-generating unit. Curr Opin Neurobiol 31, 72-80.

[52] Steriade M, Nuñez A, Amzica F (1993) Intracellular analysis of relations between the slow $(<1 \mathrm{~Hz})$ neocortical oscillation and other sleep rhythms of the electroencephalogram. J Neurosci 13, 3266-3283.

[53] Steriade M, Amzica F (1998) Coalescence of sleep rhythms and their chronology in corticothalamic networks. Sleep Res Online 1, 1-10.

[54] Steriade M (2000) Corticothalamic resonance, states of vigilance and mentation. Neuroscience 101, 243-276.

[55] Dodart JC, Meziane H, Mathis C, Bales KR, Paul SM, Ungerer A (1999) Behavioral disturbances in transgenic mice overexpressing the V717F beta-amyloid precursor protein. Behav Neurosci 113, 982-990.
[56] Games D, Adams D, Alessandrini R, Barbour R, Berthelette P, Blackwell C, Carr T, Clemens J, Donaldson T, Gillespie F, et al. (1995) Alzheimer-type neuropathology in transgenic mice overexpressing V717F beta-amyloid precursor protein. Nature 373, 523-527.

[57] Masliah E, Sisk A, Mallory M, Games D (2001) Neurofibrillary pathology in transgenic mice overexpressing V717F beta-amyloid precursor protein. J Neuropathol Exp Neurol 60, 357-368.

[58] Wang J, Ikonen S, Gurevicius K, van Groen T, Tanila H (2002) Alteration of cortical EEG in mice carrying mutated human APP transgene. Brain Res 943, 181-190.

[59] Platt B, Drever B, Koss D, Stoppelkamp S, Jyoti A, Plano A, Utan A, Merrick G, Ryan D, Melis V, Wan H, Mingarelli M, Porcu E, Scrocchi L, Welch A, Riedel G (2011) Abnormal cognition, sleep, EEG and brain metabolism in a novel knock-in Alzheimer mouse, PLB1. PLoS One 6, e27068.

[60] Hu MM, Yan XD, Zhang XM, Bai Y, Zhao F, Qi JS (2018) Application of wireless neuronal recording system in fear conditioning of Alzheimer's disease mice - hippocampal Theta oscillation observation. Sheng Li Xue Bao 70, 571578.

[61] Mondragón-Rodríguez S, Salas-Gallardo A, GonzálezPereyra P, Macías M, Ordaz B, Peña-Ortega F, AguilarVázquez A, Orta-Salazar E, Díaz-Cintra S, Perry G, Williams S (2018) Phosphorylation of Tau protein correlates with changes in hippocampal theta oscillations and reduces hippocampal excitability in Alzheimer's model. $J$ Biol Chem 293, 8462-8472.

[62] Sasaguri H, Nilsson P, Hashimoto S, Nagata K, Saito T, De Strooper B, Hardy J, Vassar R, Winblad B, Saido TC (2017) APP mouse models for Alzheimer's disease preclinical studies. EMBO J 36, 2473-2487.

[63] Sakakibara Y, Sekiya M, Saito T, Saido TC, Iijima KM (2018) Cognitive and emotional alterations in App knock-in mouse models of $A \beta$ amyloidosis. BMC Neurosci 19, 46.

[64] Peng KY, Mathews PM, Levy E, Wilson DA (2017) Apolipoprotein E4 causes early olfactory network abnormalities and short-term olfactory memory impairments. Neuroscience 343, 364-371.

[65] Chen L, Yin D, Wang TX, Guo W, Dong H, Xu Q, Luo YJ, Cherasse Y, Lazarus M, Qiu ZL, Lu J, Qu WM, Huang ZL (2016) Basal forebrain cholinergic neurons primarily contribute to inhibition of electroencephalogram delta activity, rather than inducing behavioral wakefulness in mice. Neuropsychopharmacology 41, 2133-2146.

[66] Hartman RE, Izumi Y, Bales KR, Paul SM, Wozniak DF, Holtzman DM (2005) Treatment with an amyloid-beta antibody ameliorates plaque load, learning deficits, and hippocampal long-term potentiation in a mouse model of Alzheimer's disease. J Neurosci 25, 6213-6220.

[67] Klimesch W, Doppelmayr M, Schimke H, Ripper B (1997) Theta synchronization and alpha desynchronization in a memory task. Psychophysiology 34, 169-176.

[68] Klimesch W (1999) EEG alpha and theta oscillations reflect cognitive and memory performance: A review and analysis. Brain Res Brain Res Rev 29, 169-195.

[69] Van Winsum W, Sergeant J, Geuze R (1984) The functional significance of event-related desynchronization of alpha rhythm in attentional and activating tasks. Electroencephalogr Clin Neurophysiol 58, 519-524.

[70] Sergeant J, Geuze R, van Winsum W (1987) Event-related desynchronization and P300. Psychophysiology 24, 272277. 
[71] Babiloni C, Carducci F, Cincotti F, Rossini PM, Neuper C, Pfurtscheller G, Babiloni F (1999) Human movementrelated potentials vs desynchronization of EEG alpha rhythm: A high-resolution EEG study. Neuroimage 10, 658-665.

[72] Claus JJ, Strijers RL, Jonkman EJ, Ongerboer de Visser BW, Jonker C, Walstra GJ, Scheltens P, van Gool WA (1999) The diagnostic value of electroencephalography in mild senile Alzheimer's disease. Clin Neurophysiol 110, 825-832.

[73] Bennys K, Rondouin G, Vergnes C, Touchon J (2001) Diagnostic value of quantitative EEG in Alzheimer disease. Neurophysiol Clin 31, 153-160.

[74] Lehmann C, Koenig T, Jelic V, Prichep L, John RE, Wahlund LO, Dodge Y, Dierks T (2007) Application and comparison of classification algorithms for recognition of Alzheimer's disease in electrical brain activity (EEG). J Neurosci Methods 161, 342-350.

[75] Bonanni L, Thomas A, Tiraboschi P, Perfetti B, Varanese S, Onofrj M (2008) EEG comparisons in early Alzheimer's disease, dementia with Lewy bodies and Parkinson's disease with dementia patients with a 2-year follow-up. Brain 131, 690-705.

[76] Ommundsen N, Engedal K, Øksengård AR (2011) Validity of the quantitative EEG statistical pattern recognition method in diagnosing Alzheimer's disease. Dement Geriatr Cogn Disord 31, 195-201.

[77] Lassalle JM, Halley H, Daumas S, Verret L, Francés B (2008) Effects of the genetic background on cognitive performances of TG2576 mice. Behav Brain Res 191, 104-110.

[78] Steriade M (2003) Cerebello-cerebral interactions during states of vigilance. Cerebellum 2, 82-83.

[79] Rector DM, Topchiy IA, Carter KM, Rojas MJ (2005) Local functional state differences between rat cortical columns. Brain Res 1047, 45-55.

[80] Rector DM, Schei JL, Van Dongen HP, Belenky G, Krueger JM (2009) Physiological markers of local sleep. Eur J Neurosci 29, 1771-1778.

[81] Krueger JM, Obal F (1993) A neuronal group theory of sleep function. J Sleep Res 2, 63-69. 